\title{
Organochlorine pesticides and polycyclic aromatic hydrocarbons in water and sediment of the Bosten Lake, Northwest China
}

\author{
SHEN Beibei ${ }^{1,2}$, WU Jinglu ${ }^{1 *}$, ZHAO Zhonghua ${ }^{1}$ \\ ${ }^{1}$ State Key Laboratory of Lake and Environmental Sciences, Nanjing Institute of Geography and Limnology, Chinese Academy \\ of Sciences, Nanjing 210008, China; \\ ${ }^{2}$ University of Chinese Academy of Sciences, Beijing 100049, China
}

\begin{abstract}
We evaluated organic pollution in Bosten Lake, Xinjiang, China, by measuring the concentrations and distributions of organochlorine pesticides (OCPs) and polycyclic aromatic hydrocarbons (PAHs). Water and sediment samples were collected from 19 sites (B1-B19) in the lake for analysis. Our analytical results show that the concentrations of total OCPs in water ranges from 30.3 to $91.6 \mathrm{ng} / \mathrm{L}$ and the concentrations of PAHs ranges from undetectable (ND) to $368.7 \mathrm{ng} / \mathrm{L}$. The concentrations of total OCPs in surface (i.e., lake bottom) sediment ranges from 6.9 to $16.7 \mathrm{ng} / \mathrm{g}$ and the concentrations of PAHs ranges from 25.2 to $491.0 \mathrm{ng} / \mathrm{g}$. Hexachlorocyclohexanes (HCHs) and dichlorodiphenyltrichloroethanes (DDTs) account for large proportions of the OCPs. Low $\alpha$ - to $\gamma$-HCH ratios in both water and sediment samples indicate possible contributions from both industrial products and lindane. DDTs in water are probably from historical input, whereas DDTs in sediments are from both historical and recent inputs. Moreover, DDT products in both water and sediments were from multiple sources in the northwestern part of the lake (B11, B12, B13, and B14). Fugacity ratios for DDT isomers $\left(p, p^{\prime}\right.$-DDE and $p, p^{\prime}$-DDT) at these sites were generally higher than equilibrium values. These results suggest that the input from the Kaidu River and diffusion of DDTs from the sediment to the water are responsible for DDT pollution in the water. Lower-molecular-weight PAHs, which originate primarily from wood and coal combustion and petroleum sources, represent the major fraction of the PAHs in both water and sediment samples. Our findings indicate that OCPs and PAHs in Bosten Lake can be attributed primarily to human activities. A risk assessment of OCPs and PAHs in water and sediment from Bosten Lake, however, suggests that concentrations are not yet high enough to cause adverse biological effects on the aquatic ecosystem.
\end{abstract}

Keywords: organochlorine pesticides (OCPs); polycyclic aromatic hydrocarbons (PAHs); Bosten Lake; surface water and sediment; spatial distribution

Citation: SHEN Beibei, WU Jinglu, ZHAO Zhonghua. 2017. Organochlorine pesticides and polycyclic aromatic hydrocarbons in water and sediment of the Bosten Lake, Northwest China. Journal of Arid Land, 9(2): 287-298. doi: $10.1007 / \mathrm{s} 40333-017-0008-4$

\section{Introduction}

Organochlorine pesticides (OCPs) and polycyclic aromatic hydrocarbons (PAHs) have attracted widespread attentions because of their persistence, toxicity, bioaccumulation, and semi-volatility. OCPs were used as insecticides, herbicides and fungicides in agriculture, but have been designated as persistent organic pollutants and banned for many years in some countries. However, OCPs are still detected in water, soil, and sediments in some regions. PAHs are derived

*Corresponding author: WU Jinglu (E-mail: w.jinglu@niglas.ac.cn)

Received 2016-03-01; revised 2016-07-28; accepted 2016-11-24

(C) Xinjiang Institute of Ecology and Geography, Chinese Academy of Sciences, Science Press and Springer-Verlag Berlin Heidelberg 2017 
mainly from anthropogenic origin, e.g., incomplete burning of fuels, garbage, or other organic substances (Kim et al., 2013). OCPs and PAHs enter the aquatic environment via discharge of industrial wastewater and domestic sewage, runoff from non-point sources, wet or dry depositions, etc., which are hydrophobic and tend to accumulate in sediments. Nevertheless, sediments can also be sources, from which OCP and PAH residues can be reintroduced into the water (Liu et al., 2013; Li et al., 2014).

In the past few decades, many studies have been conducted on the occurrence, fate, and transport of OCPs and PAHs in various environments associated with intense human activities (Iwata et al., 1995; Helm et al., 2011; Lu et al., 2012; Liu et al., 2013, 2014). Little information is available regarding OCPs or PAHs in arid areas of China.

Bosten Lake, the largest inland freshwater lake in China, is located in the arid region of Xinjiang. It is an important water source that supports local ecological services and economic development. Recent anthropogenic activities in the drainage basin have, however, caused environmental problems in Bosten Lake. Previous studies of Bosten Lake focused mainly on the history of PAH pollution, climate and environmental changes, and water quality (Guo et al., 2010; Zhang et al., 2010; Ma et al., 2011; Wu et al., 2014), but the OCP and PAH concentrations had not been scrutinized thoroughly. In this study, we determined the concentrations of OCPs and PAHs in surface water and sediments of Bosten Lake to: (1) identify their sources and delineate the spatial distributions in the lake; and (2) examine the potential eco-toxicities of these pollutants.

\section{Materials and methods}

\subsection{Study area}

Bosten Lake $\left(41^{\circ} 56^{\prime}-42^{\circ} 14^{\prime} \mathrm{N}, 86^{\circ} 40^{\prime}-87^{\circ} 56^{\prime} \mathrm{E}\right.$; $1051 \mathrm{~m}$ a.s.1.), the largest inland freshwater lake in China, is located in the southeastern part of the Yanqi Basin (Fig. 1). It has a maximum length of $81 \mathrm{~km}$ and a maximum width of $42 \mathrm{~km}$. It covers a surface area of $1005 \mathrm{~km}^{2}$ (Wu et al., 2014). There are 13 rivers around the lake and Kaidu River is the only non-seasonal one that is the most important water contributor of the Lake, accounting for about $83 \%$ of the lake's water inflow. Bosten Lake is also the headwaters of the Konqi River. The lake plays an important role in mitigating floods from the Kaidu River. It also serves as a potable water supply and provides water for agriculture and natural ecosystems. Besides the agricultural wastewater discharges into the lake from the northwestern corner, the lake also acts as a sink for municipal sewage and industrial wastewater, leading to a continuous deterioration of the water quality (Liu et al., 2015).

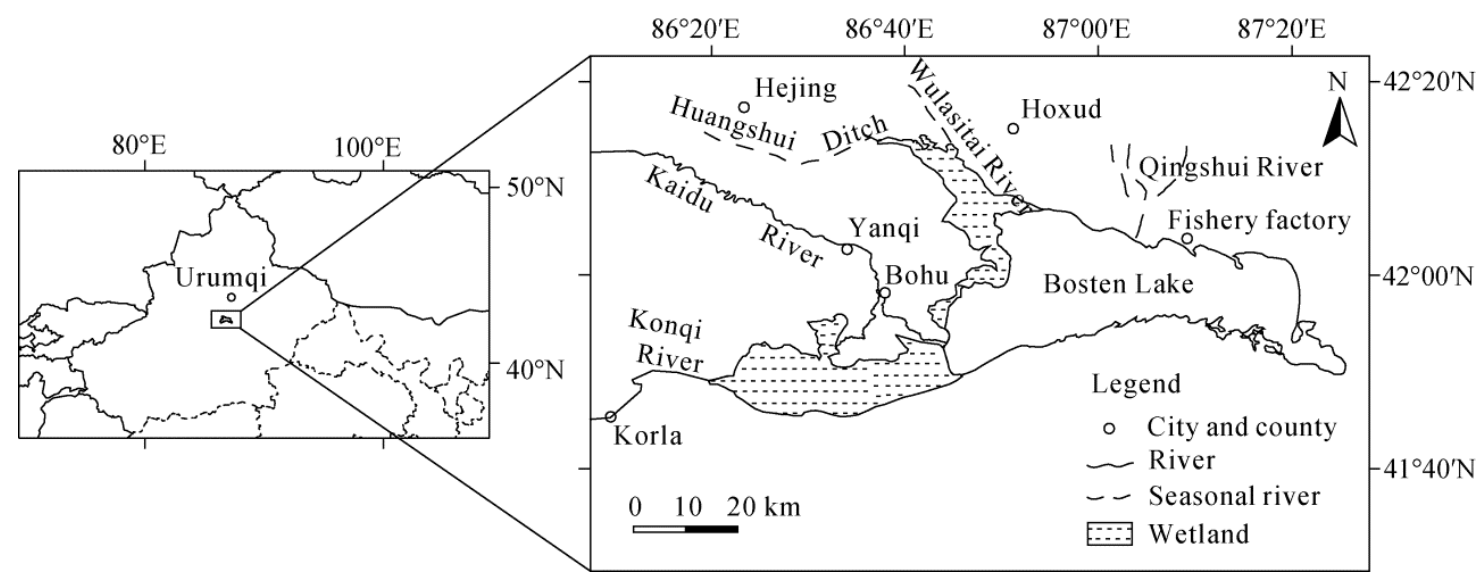

Fig. 1 Location of Bosten Lake and its river system

\subsection{Sampling and sample pretreatment}

Water and sediment samples were collected from 19 sampling sites in Bosten Lake (Fig. 2) in July 2014 for OCP and PAH analysis. The global positioning system was used to identify the location 
of each sampling site. Surface water samples were collected at $0.5 \mathrm{~m}$ below the water surface, filtered through a GF/C glass fiber filter and stored in 2-L pre-cleaned amber glass bottles at $4{ }^{\circ} \mathrm{C}$. And, they were analyzed within $12 \mathrm{~h}$ after the sampling. The water samples were then forced through solid-phase extraction (SPE) columns that were eluted sequentially with $10 \mathrm{~mL}$ methanol and $10 \mathrm{~mL}$ deionized water. The samples were eluted twice with $10 \mathrm{~mL}$ dichloromethane solution. The SPE extracts were evaporated to a near-dry state by a rotary evaporator (Buchi R-200, Flawil, Switzerland), re-dissolved in $5 \mathrm{~mL}$ hexane and then concentrated to $1 \mathrm{~mL}$ under a gentle stream of nitrogen, transferred into a vial and kept at $-20^{\circ} \mathrm{C}$ before instrumental analysis.

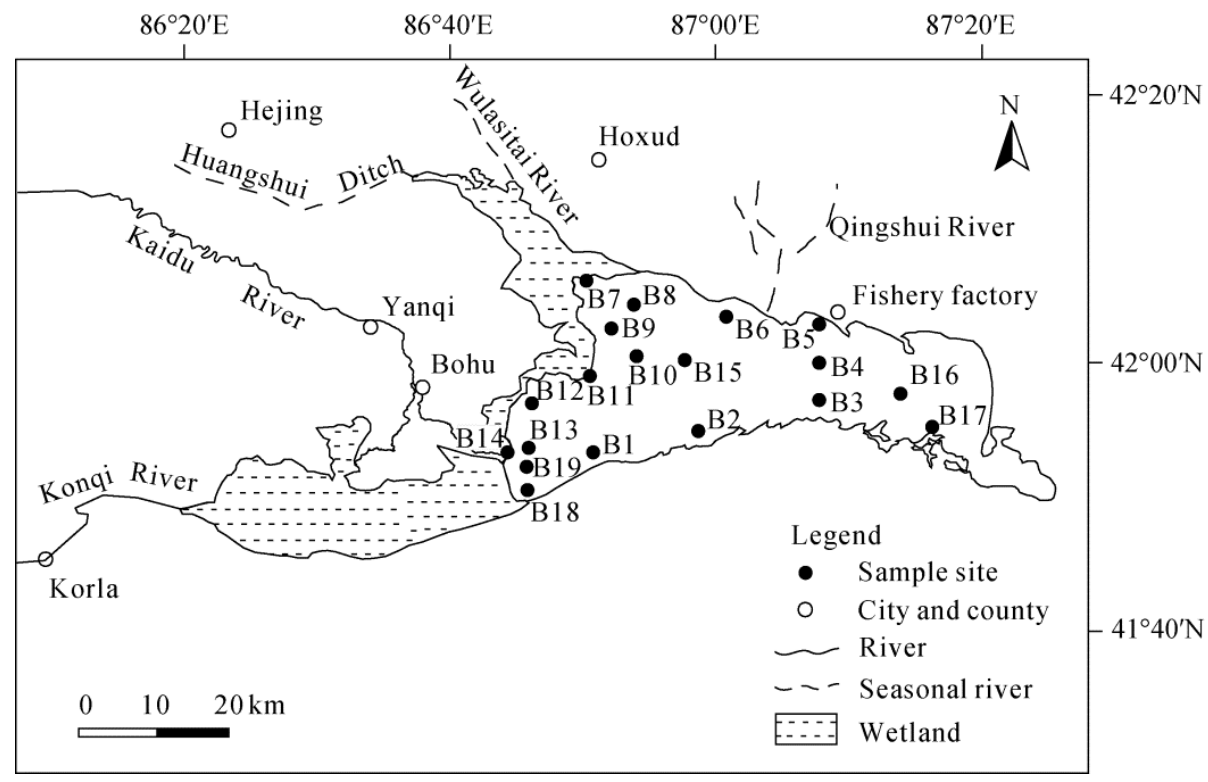

Fig. 2 Location of sampling sites in Bosten Lake

Surface sediment (i.e., $5 \mathrm{~cm}$ from the lake bottom) samples were collected in polyethylene bags with a Peterson grab sampler and stored at $4{ }^{\circ} \mathrm{C}$ during transport to the laboratory. Sediment samples were freeze-dried and ground with a mortar and pestle to obtain $100-\mu$ samples. Five-gram samples of homogenized sediment were extracted by accelerated solvent extraction (ASE-100, Dionex, USA) using dichloromethane, and mixed with copper to remove sulfur. The extracts were collected in a bottle and evaporated to a near-dry state by a rotary evaporator (Buchi R-200, Flawil, Switzerland), then re-dissolved with $5 \mathrm{~mL}$ hexane to remove dichloromethane. Solutions were purified by passing them through a glass column filled with silica gel-alumina $(2: 1)$ at the top and anhydrous sodium sulfate $(1 \mathrm{~cm})$ at the bottom. The column was eluted with $70 \mathrm{~mL} n$-hexane/dichloromethane $(\mathrm{v} / \mathrm{v}=5 / 2)$. The $\mathrm{n}$-hexane/dichloromethane elution was evaporated to a near-dry state by a rotary evaporator, re-dissolved in $5 \mathrm{~mL}$ hexane, concentrated to $1 \mathrm{~mL}$ under a gentle stream of nitrogen, then transferred to a vial and kept at $-20^{\circ} \mathrm{C}$ before instrument analysis.

\subsection{Chemicals and reagents}

A mixture of standard OCPs (containing $\alpha-\mathrm{HCH}, \beta-\mathrm{HCH}, \gamma-\mathrm{HCH}, \delta-\mathrm{HCH}$, heptachlor, aldrin, heptachlor epoxide, $\alpha$-chlordane, $\gamma$-chlordane, dieldrin, endrin, endrin aldehyde, endrin ketone, $\alpha$-endosulfan, $\beta$-endosulfan, $p, p^{\prime}$-DDE, $p, p^{\prime}$-DDD, $p, p^{\prime}$-DDT, endosulfan sulfate, and methoxychlor), recovery surrogates standard (2-, 4-, 5-, 6-tetrachloro-m-xylene (TCmX)) and decachlorobiphenyl (PCB209) and internal standard (pentachloronitrobenzene (PCNB)) was purchased from Supelco (USA). Standards of 16 United States Environmental Protection Agency (USEPA) priority PAHs (containing naphthalene (Nap), acenaphthylene (Acy), acenaphthene (Ace), fluorine (Fl), phenanthrene (Phe), anthracene (Ant), fluoranthene (Flu), pyrene (Pyr), benzo[a]anthracene $(\mathrm{BaA})$, chrysene $(\mathrm{Chr})$, benzo[b]fluoranthene $(\mathrm{BbF})$, benzo[k]fluoranthene 
$(\mathrm{BkF})$, benzo[a]pyrene $(\mathrm{BaP})$, indeno[1,2,3-cd]pyrene (IcdP), dibenzo[ah]anthracene (DahA), and benzo[ghi]perylene (BghiP)), deuterated recovery surrogates standard (consisting of naphthalene-D8, acenaphthene-D10, phenanthrene-D10, chrysene-D12, and perylene-D12) and the internal standard (hexamethylbenzene) were purchased from Supelco (USA). Dichloromethane, methanol, and n-hexane were also obtained from Supelco. All organic solvents were HPLC grade.

\subsection{Instrumental analysis}

OCP concentrations were determined by gas chromatography equipped with a ${ }^{63} \mathrm{Ni}$ electron capture detector (GC-ECD: 7890 GC Agilent, USA). A DB-5MS capillary column $(30 \mathrm{~m} \times 0.25$ $\mathrm{mm} \times 0.25 \mu \mathrm{m})$ was used for separation. The oven temperature was programmed to range from $60^{\circ} \mathrm{C}$ to $170^{\circ} \mathrm{C}(2 \mathrm{~min}$ hold $)$ at the rate of $10^{\circ} \mathrm{C} / \mathrm{min}$, and from $170^{\circ} \mathrm{C}$ to $280^{\circ} \mathrm{C}(3 \mathrm{~min}$ hold $)$ at the rate of $5^{\circ} \mathrm{C} / \mathrm{min}$, and finally from $280^{\circ} \mathrm{C}$ to $300^{\circ} \mathrm{C}$ at the rate of $15^{\circ} \mathrm{C} / \mathrm{min}$. Temperatures of the injector and detector were $250^{\circ} \mathrm{C}$ and $320^{\circ} \mathrm{C}$, respectively. Helium was used as the carrier gas $(1.5$ $\mathrm{mL} / \mathrm{min})$ and nitrogen as the make-up gas $(60 \mathrm{~mL} / \mathrm{min})$. One $\mu \mathrm{L}$ of sample was injected in the splitless mode for analysis. Identification of OCPs was confirmed using GC-MS (Agilent 7890-5975C) equipped with a HP-5MS capillary column $(30 \mathrm{~m} \times 0.32 \mathrm{~mm} \times 0.25 \mu \mathrm{m})$.

PAHs analyses were carried out using a high performance liquid chromatograph (HPLC) (Agilent 1200 HPLC) equipped with diode array detection (DAD, $238 \mathrm{~nm}$ ) coupled with a fluorescence detector (FLD). The separation column was a WATERS PAH C18 $(5 \mu \mathrm{m} \times 460$ $\mathrm{mm} \times 0.25 \mu \mathrm{m})$. The mobile phase was a gradient of acetonitrile and purified water $(60 \%$ acetonitrile at first; after $20 \mathrm{~min}$, linear gradient to $100 \%$ acetonitrile held for $10 \mathrm{~min}$; flow rate: 1 $\mathrm{mL} / \mathrm{min})$. The injection volume was $20 \mu \mathrm{L}$.

\subsection{Quality assurance and quality control}

Concentrations of OCPs and PAHs were quantified by peak identification and retention times of corresponding standard components. Blanks, duplicate samples, and internal standard additions were employed for analytical assurance. The surrogate recoveries were $68 \%-112 \%$ for OCPs and $76 \%-103 \%$ for PAHs. The detection limits were $0.01-2.00 \mathrm{ng} / \mathrm{L}$ and $0.01-2.81 \mathrm{ng} / \mathrm{g}$ for OCPs, and $0.02-0.08 \mathrm{ng} / \mathrm{L}$ and $0.03-3.57 \mathrm{ng} / \mathrm{g}$ for PAHs.

\subsection{Fugacity ratios calculation}

The fugacity value can be used to estimate the net flux direction of a pollutant between compartments (Mackay, 2001). The sediment-water fugacity ratio $\left(f_{\mathrm{s}} / f_{\mathrm{w}}\right)$ is calculated as Equation 1 (Mackay, 2001; Dai et al., 2014):

$$
f_{\mathrm{s}} / f_{\mathrm{w}}=C_{\mathrm{s}} /\left(C_{\mathrm{w}} \times 0.410 \mathrm{OC} \times K_{\mathrm{ow}} \times \rho_{\mathrm{s}}\right) .
$$

Where $f_{\mathrm{w}}$ and $f_{\mathrm{s}}$ are the fugacity $(\mathrm{Pa})$ in water and sediment, respectively. $C_{\mathrm{w}}$ and $C_{\mathrm{s}}$ are the concentrations of the DDT isomer in water $(\mathrm{ng} / \mathrm{L})$ and sediment $(\mathrm{ng} / \mathrm{g})$, respectively. OC, the organic carbon content $(\%) ; K_{\mathrm{ow}}$, the octanol-water partition coefficient; $\rho_{\mathrm{s}}$, the sediment density $(\mathrm{kg} / \mathrm{L})$. The $K_{\mathrm{ow}}$ values for $p, p^{\prime}-\mathrm{DDT}, p, p^{\prime}$-DDE and $p, p^{\prime}$-DDD were taken from Unitednations Environment Programme (UNEP) Chemicals (2002). The value of $f_{\mathrm{s}} / f_{\mathrm{w}}$ at $1.0 \mathrm{implies}$ that the DDTs in water and sediment are at equilibrium and the net flux is therefore zero. $f_{\mathrm{s}} / f_{\mathrm{w}}>1.0$ and $f_{\mathrm{s}} / f_{\mathrm{w}}<1.0$ indicate net diffusion from the sediment to the water and net deposition from the water to the sediment, respectively (Dai et al., 2014).

\section{Results}

\subsection{Concentration and composition of OCPs in water and sediments}

The concentration of total OCPs in water ranged from 30.3 to $91.6 \mathrm{ng} / \mathrm{L}$, with an average concentration of $55.2 \mathrm{ng} / \mathrm{L}$. The concentration ranged from 6.9 to $16.7 \mathrm{ng} / \mathrm{g}$ in sediments, with a mean value of $11.1 \mathrm{ng} / \mathrm{g}$ (Table 1). Among OCPs, DDTs and HCHs were the most abundant compounds both in water and sediments. DDTs ( $p, p^{\prime}$-DDD, $p, p^{\prime}$-DDE and $\left.p, p^{\prime}-\mathrm{DDT}\right)$ were in the range of $0.7-40.0 \mathrm{ng} / \mathrm{L}$ and $0.1-4.5 \mathrm{ng} / \mathrm{g}$ in water and sediments, respectively. $\mathrm{HCHs}(\alpha-\mathrm{HCH}$, 
$\beta-\mathrm{HCH}, \gamma-\mathrm{HCH}$, and $\delta-\mathrm{HCH})$ were in the range of $14.2-24.5 \mathrm{ng} / \mathrm{L}$ and $2.0-7.1 \mathrm{ng} / \mathrm{g}$ in water and sediments, respectively. In terms of individual component distributions, $p, p^{\prime}$-DDT was the major pollutant of DDTs both in water and sediments. And $\alpha-\mathrm{HCH}$ and $\beta-\mathrm{HCH}$ were the major pollutants of $\mathrm{HCHs}$ in water and sediments, respectively.

Table 1 Concentrations of organochlorine pesticides (OCPs) in surface water and sediments (dry weight) in Bosten Lake

\begin{tabular}{|c|c|c|c|c|}
\hline \multirow{2}{*}{ OCPs } & \multicolumn{2}{|c|}{ Water (ng/L) } & \multicolumn{2}{|c|}{ Sediments (ng/g) } \\
\hline & Range & Mean & Range & Mean \\
\hline$\alpha-\mathrm{HCH}$ & $4.6-7.0$ & 5.7 & $0.9-1.1$ & 0.9 \\
\hline$\beta-\mathrm{HCH}$ & $5.0-6.0$ & 5.1 & $1.0-1.6$ & 1.2 \\
\hline$\gamma-\mathrm{HCH}$ & ND-6.1 & 3.9 & ND-1.0 & 0.8 \\
\hline$\delta-\mathrm{HCH}$ & ND-7.3 & 3.4 & ND-4.4 & 1.2 \\
\hline$p, p^{\prime}-\mathrm{DDE}$ & $0.7-2.1$ & 1.1 & $0.1-0.2$ & 0.2 \\
\hline$p, p^{\prime}-\mathrm{DDD}$ & ND & ND & ND-0.4 & 0.03 \\
\hline$p, p^{\prime}$-DDT & ND-37.9 & 3.7 & ND-4.0 & 1.9 \\
\hline$\gamma$-Chordane & ND-1.3 & 0.8 & $\mathrm{ND}-0.3$ & 0.2 \\
\hline$\alpha$-Chordane & $0.9-1.1$ & 0.9 & $\mathrm{ND}-0.5$ & 0.2 \\
\hline Heptachlor & ND-7.7 & 6.8 & $\mathrm{ND}-1.8$ & 1.0 \\
\hline Heptachlor epoxide & ND-2.5 & 1.4 & $\mathrm{ND}-0.2$ & 0.03 \\
\hline$\alpha$-Endosulfan & ND-0.8 & 0.6 & $\mathrm{ND}-0.2$ & 0.1 \\
\hline$\beta$-Endosulfan & $2.0-2.3$ & 2.1 & ND- -0.6 & 0.3 \\
\hline Endosulfan sulfate & $0.9-1.5$ & 1.1 & $0.2-1.3$ & 0.4 \\
\hline Aldrin & ND-2.3 & 1.5 & ND-1.0 & 0.4 \\
\hline Dieldrin & $4.4-5.4$ & 4.5 & $\mathrm{ND}-1.2$ & 0.9 \\
\hline Endrin & ND-2.7 & 1.8 & $\mathrm{ND}-0.5$ & 0.3 \\
\hline Endrin aldehyde & $\mathrm{ND}-3.2$ & 1.4 & $0.2-0.6$ & 0.3 \\
\hline Endrin ketone & ND-4.4 & 3.3 & $\mathrm{ND}-0.6$ & 0.5 \\
\hline methoxychlor & ND-16.6 & 5.2 & ND-3.3 & 0.2 \\
\hline Total OCPs & $30.3-91.6$ & 55.2 & $6.9-16.7$ & 11.1 \\
\hline
\end{tabular}

Note: ND, not detected.

\subsection{Concentration and composition of PAHs in water and sediments}

Total concentration of PAHs in water ranged from ND (not detectable) to $368.7 \mathrm{ng} / \mathrm{L}$, with an average concentration of $189.7 \mathrm{ng} / \mathrm{L}$ (Table 2). The detected PAHs ranged from ND to $93.2 \mathrm{ng} / \mathrm{L}$ for a 2-ring compound (Nap; average $54.9 \mathrm{ng} / \mathrm{L}$ ), from ND to $269.0 \mathrm{ng} / \mathrm{L}$ for 3-ring compounds (Phe, Fl, Ace, Acy, Ant; average $116.4 \mathrm{ng} / \mathrm{L}$ ), and from ND to $111.5 \mathrm{ng} / \mathrm{L}$ for 4-ring compounds (Flu, Pyr, BaA, Chr; average 18.4 ng/L). However, 5- and 6-ring PAHs (BbF, BkF, BaP, DahA, BghiP and IcdP) were not detected at any site. The compositional profile of PAHs in water showed that 2- and 3-ring PAHs were abundant, accounting for $29 \%$ and $61 \%$ of total PAHs, respectively (Fig. 3). For the individual compounds, Nap and Phe were the major pollutants, accounting for $29 \%$ and $38 \%$ of total PAHs, respectively.

Concentration of PAHs ranged from 25.2 to $491.0 \mathrm{ng} / \mathrm{g}$, with a mean value of $145.3 \mathrm{ng} / \mathrm{g}$ in sediments (Table 2). Concentration of the 2-ring compound ranged from 1.7 to $98.9 \mathrm{ng} / \mathrm{g}$ (average $26.5 \mathrm{ng} / \mathrm{g}$ ), concentration of 3-ring compounds ranged from 12.8 to $343.4 \mathrm{ng} / \mathrm{g}$ (average 100.6 $\mathrm{ng} / \mathrm{g}$ ), concentration of 4-ring compounds ranged from ND to $46.7 \mathrm{ng} / \mathrm{g}$ (average $17.6 \mathrm{ng} / \mathrm{g}$ ), and concentration of 5-ring compounds ranged from ND to $2.0 \mathrm{ng} / \mathrm{g}$ (average $0.5 \mathrm{ng} / \mathrm{g}$ ). However, 6-ring PAHs were not detected in any sediment sample. The compositional profile of PAHs in sediments showed that 3-ring PAHs were abundant, accounting for $69 \%$ of total PAHs (Fig. 3). Among the individual compounds, Nap, Acy and Phe were the major pollutants, accounting for $18 \%, 19 \%$ and $37 \%$ of total PAHs, respectively. 
Table 2 Concentrations of polycyclic aromatic hydrocarbons (PAHs) in surface water and sediments (dry weight) in Bosten Lake

\begin{tabular}{|c|c|c|c|c|}
\hline \multirow{2}{*}{ PAHs } & \multicolumn{2}{|c|}{ Water (ng/L) } & \multicolumn{2}{|c|}{ Sediments (ng/g) } \\
\hline & Range & Mean & Range & Mean \\
\hline Nap & ND-93.2 & 54.9 & $1.7-98.9$ & 26.5 \\
\hline Acy & ND-109.3 & 17.3 & ND-243.6 & 27.8 \\
\hline Ace & ND-42.2 & 7.7 & ND-3.7 & 1.1 \\
\hline $\mathrm{Fl}$ & ND-28.2 & 12.1 & $1.3-37.2$ & 16.1 \\
\hline Phe & ND-140.4 & 71.9 & $9.1-101.8$ & 53.3 \\
\hline Ant & ND-30.9 & 7.5 & ND-7.6 & 2.3 \\
\hline Flu & ND-14.2 & 0.9 & ND-0.3 & 0.03 \\
\hline Pyr & ND-53.8 & 6.5 & ND-10.7 & 4.1 \\
\hline $\mathrm{BaA}$ & ND-57.7 & 7.5 & ND-37.2 & 13.5 \\
\hline $\mathrm{Chr}$ & ND-23.9 & 3.5 & $\mathrm{ND}$ & ND \\
\hline $\mathrm{BbF}$ & ND & ND & ND & ND \\
\hline $\mathrm{BkF}$ & ND & ND & ND-0.3 & 0.03 \\
\hline $\mathrm{BaP}$ & ND & ND & ND-2.0 & 0.5 \\
\hline DahA & ND & ND & ND & ND \\
\hline BghiP & ND & ND & ND & ND \\
\hline IcdP & ND & ND & ND & ND \\
\hline Total PAHs & ND-368.7 & 189.7 & $25.2-491.0$ & 145.3 \\
\hline
\end{tabular}

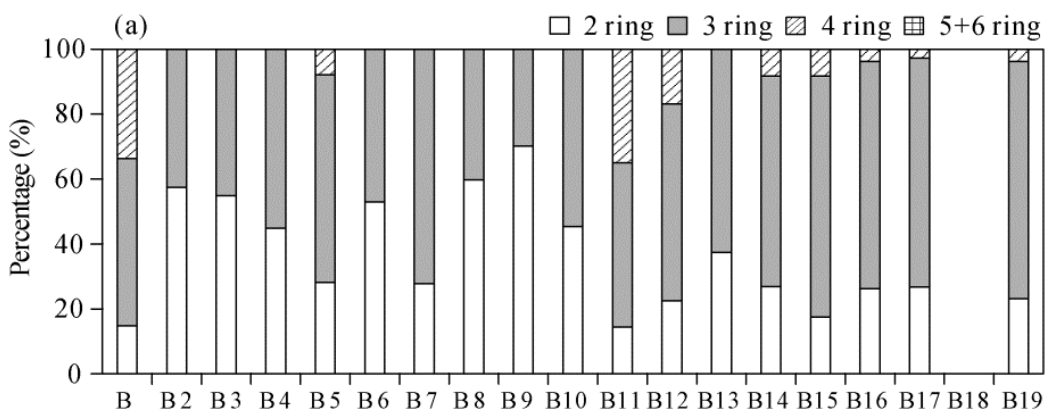

(b)

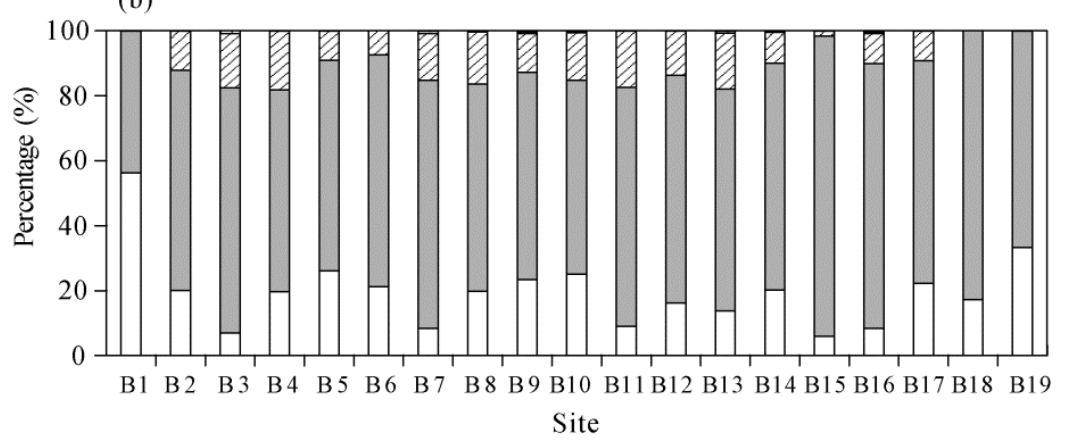

Fig. 3 Distribution of polycyclic aromatic hydrocarbons (PAHs) with different ring numbers in water (a) and sediments (b) in Bosten Lake

\section{Discussion}

\subsection{Residual OCP and PAH concentrations in Bosten Lake}

We evaluated organic pollutant levels in Bosten Lake (i.e., the concentrations of OCPs and PAHs in water and sediments) and compared the values with those from other lakes (Table 3). DDTs and 
HCHs in Bosten Lake water and sediments were slightly higher than those of the lakes in developed countries, whereas PAHs were comparatively lower (Helm et al., 2011; Montuori and Triassi, 2012; Ok et al., 2013; Montuori et al., 2014). In addition, DDTs in Bosten Lake water were slightly higher than those measured in Poyang Lake and Baiyangdian Lake, China, and $\mathrm{HCHs}$ were higher than those in Baiyangdian Lake. PAHs were only higher than those in Poyang Lake. In terms of sediment samples, DDTs, HCHs and PAHs were generally lower than those in other lakes in China. It can be concluded that DDT and HCH levels in Bosten Lake are generally lower compared with the other lakes in China, but are on the high end with respect to worldwide lakes. PAHs in Bosten Lake were lower than those in all of other lakes (China and worldwide). Relative to Bosten Lake, water systems with higher OCP levels in China lie within major agricultural areas and the high OCPs detected in those regions are consequences of crop production although they were banned over 30 years ago (i.e., 1983). Slightly higher DDT and $\mathrm{HCHs}$ in Bosten Lake water may be contributed partially by OCP residues from soils transported into the lake via enhanced surface runoff (Santschi et al., 2001; Franců et al., 2010). Concentrations of PAHs in the environment were closely correlated with local human population, gross domestic product, number of vehicles and power generation, and thus can serve as a proxy for anthropogenic activities, especially industrial activities (Liu et al., 2012). The Bosten Lake area lies in a remote and arid area and its social and economic development levels were lower than in other regions of China. This explains the relatively low PAHs in Bosten Lake.

Table 3 Comparison of $\mathrm{HCH}$ (dichlorodiphenyltrichloroethane), DDT (hexachlorocyclohexane) and PAH (polycyclic aromatic hydrocarbon) concentrations in surface water (ng/L) and sediments (ng/g, dry weight) of selected lakes

\begin{tabular}{|c|c|c|c|c|c|}
\hline \multirow{2}{*}{ Lakes } & \multirow{2}{*}{ Sample type } & DDTs & $\mathrm{HCHs}$ & PAHs & \multirow{2}{*}{ Reference } \\
\hline & & Range (Mean) & Range (Mean) & Range (mean) & \\
\hline \multirow{2}{*}{ Bosten Lake } & Water & $0.7-40.0(5.8)$ & $14.2-24.5(18.1)$ & ND-368.7 (189.7) & \multirow{2}{*}{ This study } \\
\hline & Sediment & $0.1-4.5(2.1)$ & $2.0-7.1(4.1)$ & $25.2-491.0(145.3)$ & \\
\hline \multirow{2}{*}{ Taihu Lake ${ }^{*}$} & Water & - & - & $238-7422(1592)$ & \multirow{2}{*}{$\begin{array}{l}\text { Zhao et al. } \\
\text { (2009); Zhang et } \\
\text { al. (2011) }\end{array}$} \\
\hline & Sediment & $0.25-375(53.9)$ & $0.07-5.75(1.67)$ & $209-3843(584)$ & \\
\hline \multirow{2}{*}{ Poyang Lake ${ }^{*}$} & Water & $2.3-33.4$ & $4.4-59.7$ & $5.6-266.1$ & \multirow{2}{*}{$\begin{array}{l}\text { Lu et al. (2012); } \\
\text { Zhi et al. (2015) }\end{array}$} \\
\hline & Sediment & $14.4-82.9(46.7)$ & $0.5-6.9(2.97)$ & $33-369.1(157.0)$ & \\
\hline \multirow{2}{*}{$\begin{array}{c}\text { Baiyangdian } \\
\text { Lake }\end{array}$} & Water & $4.1-20.6(11.28)$ & $3.1-10.6(6.18)$ & $145.1-1311.6(502.6)$ & \multirow{2}{*}{$\begin{array}{l}\text { Liu et al. (2010); } \\
\text { Dai et al. (2011) }\end{array}$} \\
\hline & Sediment & $0.9-6.5(2.3)$ & $1.8-5.7(2.7)$ & $229.9-1750.0(643.4)$ & \\
\hline \multirow{2}{*}{$\begin{array}{l}\text { Baikal Lake, } \\
\text { Russia }\end{array}$} & Water & ND-0.015 & $0.056-0.96$ & - & \multirow{3}{*}{$\begin{array}{l}\text { Iwata et al. } \\
\text { (1995); Ok et al. } \\
(2013) \\
\text { Helm et al. } \\
(2011)\end{array}$} \\
\hline & Sediment & $0.014-2.70$ & $0.019-0.12$ & $220-1256$ & \\
\hline $\begin{array}{c}\text { Simcoe Lake, } \\
\text { Canada }\end{array}$ & Sediment & $<1-10(6)$ & ND & 229-5410 (1790) & \\
\hline
\end{tabular}

Note: -, not available; ${ }^{*}$, lakes in China.

\subsection{Spatial distributions and sources of OCPs and PAHs in Bosten Lake}

\subsubsection{OCPs}

The spatial distribution of OCPs in Bosten Lake is shown in Figure 4. High OCP concentrations occurred in the northwestern part of the lake, with the highest concentrations of OCPs in the water and sediments at sites B11 and B19, respectively. Yanqi is an agricultural area and there is some agricultural draining water around B11. Higher OCPs in water at site B11 can be explained by agricultural runoff. High OCPs in the sediment at site B19 may be a consequence of the fact that water from B11 and the Kaidu River (B14) mixed near site B19, leading to deposition of more pollutants in the sediment over time (Zhang et al., 2003). In addition, relatively high OCP concentrations in water also occurred near the estuary of Huangshui Ditch (B7 and B8). The lowest concentration of OCPs in water was found at site B18, located in the outlet of Bosten Lake to the Konqi River, which may be affected by massive water exchange. The spatial distributions of OCPs in water and sediments suggest that the Kaidu River, agricultural runoff and Huangshui Ditch were the main sources of pollution. 


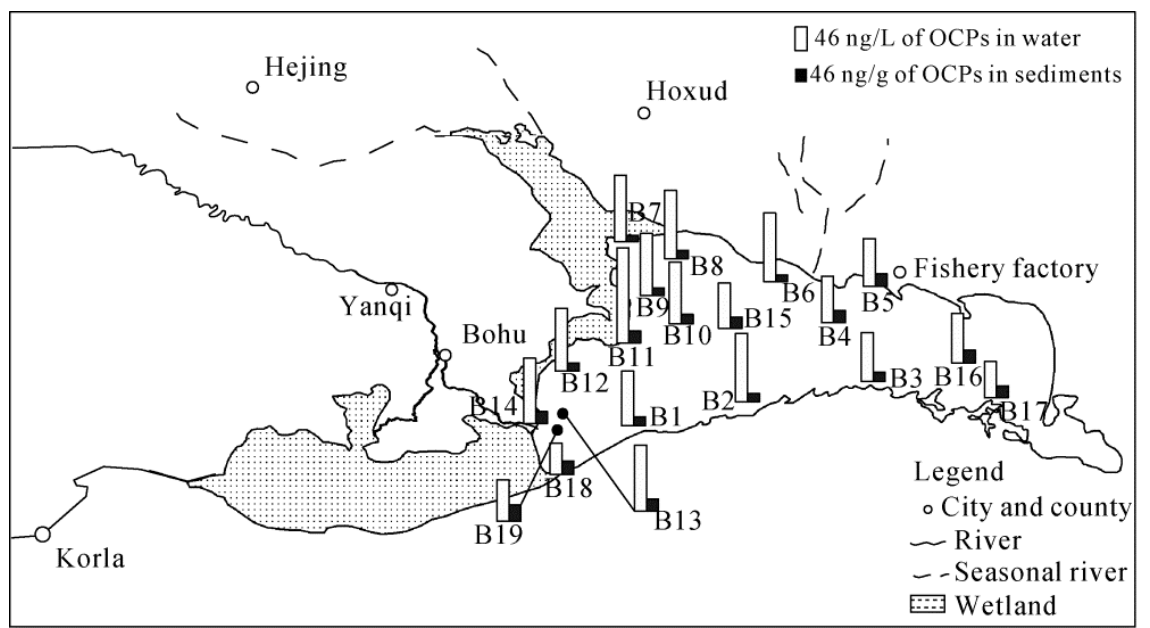

Fig. 4 OCP (organochlorine pesticide) concentrations of water and sediments in Bosten Lake

Generally, HCHs were produced by industrial products (technical HCHs) and pesticide lindane. Technical HCHs contain $60 \%-70 \% \alpha-, 5 \%-12 \% \beta-, 10 \%-15 \% \gamma-$ and $6 \%-10 \% \delta-\mathrm{HCH}$; and lindane contains nearly $99 \%$ of $\gamma-\mathrm{HCH}$. The value of $\alpha-\gamma-\mathrm{HCH}$ is $4.64-5.83$ for technical $\mathrm{HCHs}$, and a value of $\alpha-/ \gamma-\mathrm{HCH}<1$ indicates lindane input (Zhang et al., 2009). In this study, the ratios in water and sediment samples were about 1, indicating the inputs of technical HCHs and lindane at most sites. $\alpha-\mathrm{HCH}$ and $\beta-\mathrm{HCH}$ predominated $\mathrm{HCHs}$ both in water and sediments. The results suggest that long-distance transport provided the enhanced source of HCHs in the water, given the high volatility of $\alpha-\mathrm{HCH}$, and historical use of $\mathrm{HCHs}$, because $\beta-\mathrm{HCH}$ is more stable than other $\mathrm{HCH}$ isomers and can accumulate in the environment over time (Willett et al., 1998).

$p, p^{\prime}$-DDT can degrade to $p, p^{\prime}$-DDE and $p, p^{\prime}$-DDD under aerobic and anaerobic conditions, respectively. Therefore, a value of $\left(p, p^{\prime}-\mathrm{DDE}+p, p^{\prime}\right.$-DDD $) / \mathrm{DDTs}>0.5$ indicates the historical use of DDT (Qiu et al., 2004). The ratio of ( $p, p^{\prime}$-DDE $+p, p$ '-DDD)/DDTs in water and sediments in Bosten Lake ranged from 0.05 to 1.00 and 0.04 to 1.00 , respectively. The ratios in $80 \%$ of the water samples were $>0.5$ and the ratios in $40 \%$ of the sediment samples were $>0.5$, indicating the main source of DDT was weathered agricultural soils. Only at sites B11, B12, B13 and B14 were the ratios $<0.5$ in both water and sediments, indicating there was possible new pollution from the Kaidu River and agricultural runoff. Recent observations of OCPs in China revealed that a significant contribution of fresh DDT to the environment dicofol was the major contributor of DDT (Qiu et al., 2004, 2005). Dicofol is mainly used as an insecticide/herbicide in cotton crop. The Bosten Lake is surrounded by large areas of cotton fields and dicofol is of a great concern. Given that Bosten Lake is used for fishing and aquaculture, another potential DDT source is fishing boats, which in China are often tainted with antifouling material containing DDT (Lin et al., 2009). The ratios at other sites (B4, B5, B15, B16, B17, B18 and B19) were $>0.5$ in water and $<0.5$ in sediments, which may be a consequence of new inputs from the other sources, such as pollutant re-suspension resulted from sediment disturbances.

In this study, $f_{\mathrm{s}} / f_{\mathrm{w}}$ values were calculated to assess the direction of DDT exchange between the water and sediments. The values in Bosten Lake ranged from 0.76 to 4.03 for $p, p^{\prime}$-DDE and 0.96 to 2.50 for $p, p^{\prime}$-DDT (Fig. 5). Ratios within the range $0.79-1.21$ represent values that are equivocal or uncertain with respect to contaminant movement (Dai et al., 2014). In Bosten Lake, with the exception of four values for $p, p^{\prime}$-DDE and one value for $p, p^{\prime}$-DDT, calculated fugacity ratios fall outside this uncertainty range, and we concluded that for $p, p^{\prime}$-DDE and $p, p^{\prime}$-DDT, the water and sediments were not in equilibrium. Therefore, fugacity ratios for $p, p^{\prime}$-DDE and $p, p$ '-DDT in Bosten Lake indicated net transfers from the sediments to overlying water. 


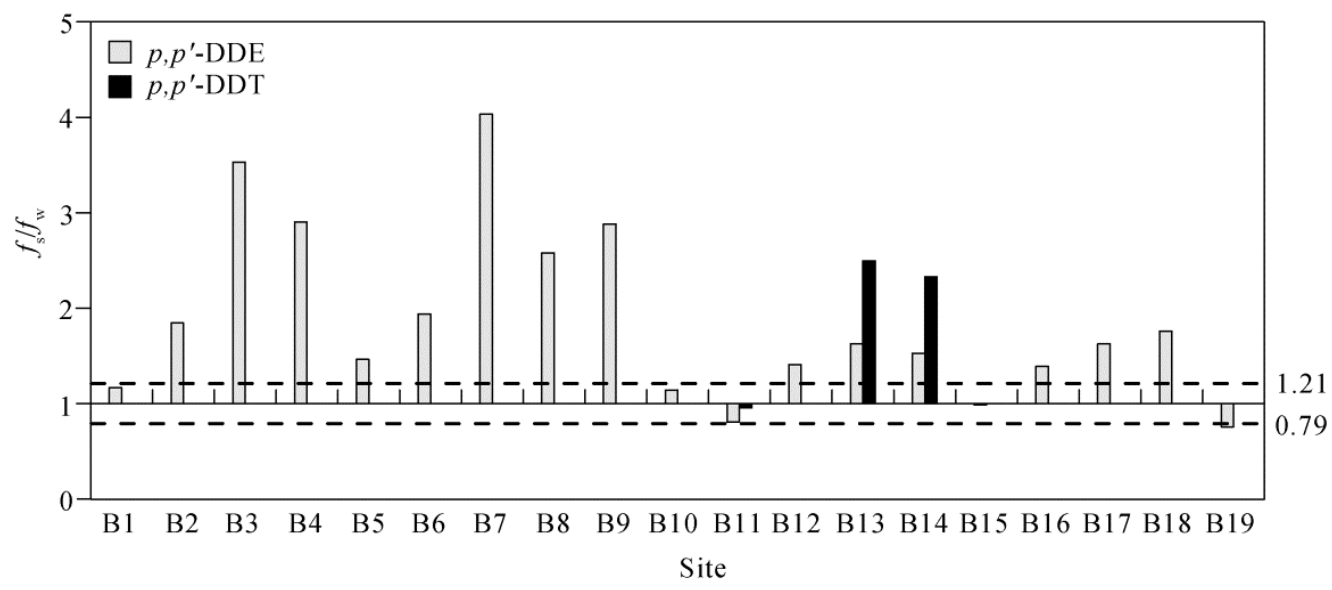

Fig. 5 Sediment-water fugacity ratios of $p, p^{\prime}$-DDE and $p, p^{\prime}$-DDT in Bosten Lake (the dotted line represented the range from 0.79 to 1.21$). f_{\mathrm{w}}$ and $f_{\mathrm{s}}$ are the fugacity $(\mathrm{Pa})$ in water and sediment, respectively.

\subsubsection{PAHs}

Concentrations of PAHs in water in the center of the lake were lower than those in water from the east and west areas of the lake. Sedimentary PAHs gradually declined from the western part to the eastern part of the lake (Fig. 6). Higher PAH concentrations in water were found at B19 (368.7 $\mathrm{ng} / \mathrm{L}), \mathrm{B} 14(324.0 \mathrm{ng} / \mathrm{L})$ and B16 (355.3 ng/L), and in sediments at B14 (491.0 ng/g) and B5 $(246.8 \mathrm{ng} / \mathrm{g})$. Spatial distributions of PAHs in water and sediments indicate that they entered the lake mainly via the Kaidu River. B5 is located near the fisheries factory where powerboats are often used. Ogata and Fujisawa (1990) reported that oil spilled from such boats could be the main source of PAH pollution. And combustion of petroleum fuels may have also contributed to PAH pollution. Pollutants in water near B16 may be attributable to the fishing and aquaculture industries, but this needs further investigation.

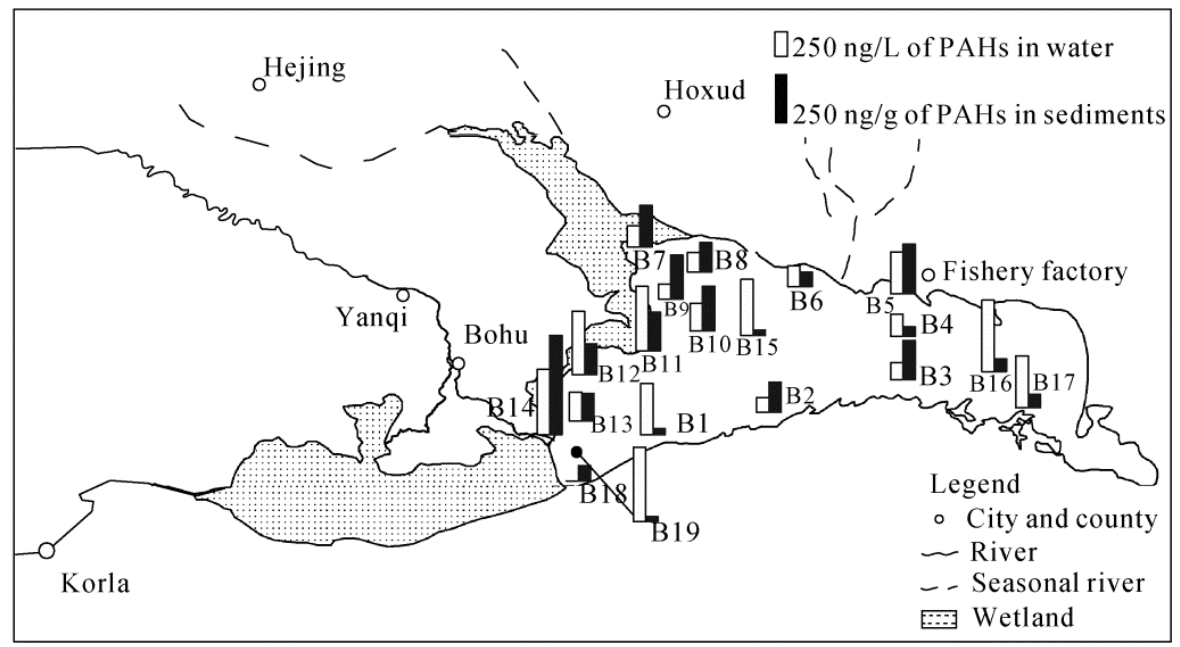

Fig. 6 Polycyclic aromatic hydrocarbon (PAH) concentrations of water and sediments in Bosten Lake

Anthropogenic PAHs come mainly from combustion of fossil fuels (pyrogenic) and discharge of petroleum-related materials (petrogenic). Petroleum-derived residues and low-temperature combustion, such as that of wood and coal, yield abundant low-molecular-weight (LMW) PAH compounds (including 2- and 3-ring PAHs), whereas high-temperature combustion processes, such as burning of petroleum fuels, can yield high concentrations of high-molecular-weight (HMW) PAHs (including 4-, 5- and 6-ring PAHs) (Harrison et al., 1996). In this study, LMW 
PAHs were the predominant compounds, accounting for $91 \%$ and $88 \%$ of the total PAHs in water and sediments, respectively (Fig. 2). This pattern of similar PAH abundance in water and sediments of Bosten Lake suggests that the pollution came primarily from the same petrogenic sources or/and from low-temperature combustion of wood and coal. Furthermore, the ratio of Ant/(Ant+Phe) was used to distinguish between combustion and petroleum sources of PAHs. The ratios in water and sediments ranged from ND to 0.2 and from ND to 0.18 , respectively. In the samples from sites B5, B11, B14, B16 and B17, the ratios showed a combustion source of PAHs in water, whereas input to sediments was from a mixture of pyrolytic and petrogenic contamination. For samples at site B15, the ratios in water and sediment were $>0.1$, suggesting that PAHs from that site were of pyrolytic origin and implying that PAHs were probably air-transported. Ant and Phe were the major PAH pollutants in water and sediments, indicating wood and coal combustion sources (Khairy and Lohmann, 2012).

\subsection{Ecological risk assessment of OCPs and PAHs in Bosten Lake}

To determine whether OCP and PAH concentrations have reached toxic levels in Bosten Lake, we compared the pollutant values with several environmental quality guideline values. According to recommendations for water samples provided by the USEPA (2002), $\gamma-\mathrm{HCH}$ concentrations in Bosten Lake were within guideline values (Criterion Continuous Concentration (CCC): $80 \mathrm{ng} / \mathrm{L}$ ); concentrations of $p, p^{\prime}$-DDT were between the CCC and Criterion Maximum Concentration (CMC) guideline values (USEPA, 2002); and the predominant PAHs, Nap and Phe, were below the CCC standards $(<620,000 \mathrm{ng} / \mathrm{L}$ for Nap, $<630 \mathrm{ng} / \mathrm{L}$ for Phe). The concentrations of HCHs, DDTs and PAHs were below the corresponding CMC and CCC. Therefore, HCH, DDT and PAH residues in Bosten Lake water are generally within safe levels.

The concentrations of primary OCPs and PAHs were compared with consensus-based sediment quality guidelines, including the threshold effect concentration (TEC) and probable effect concentration (PEC; MacDonald et al., 2000). The TEC represents the concentration below which adverse effects are not expected to occur. PEC represents the concentration above which adverse effects are expected to occur (MacDonald et al., 2000). For $p, p^{\prime}$-DDE, $p, p^{\prime}$-DDT and total DDTs in the sediments of Bosten Lake, none of the samples surpassed the TEC value ( $p, p^{\prime}$-DDE, 3.16 $\mathrm{ng} / \mathrm{g} ; p, p^{\prime}$-DDT, $4.16 \mathrm{ng} / \mathrm{g}$; total DDTs, $5.28 \mathrm{ng} / \mathrm{g}$ ). Concentrations of $\gamma-\mathrm{HCH}(\mathrm{ND}-1.0 \mathrm{ng} / \mathrm{g}$ ) were all lower than the TEC (2.37 ng/g). For PAHs, concentrations of total PAHs and main compounds (Nap and Phe) in sediments were all below the TEC levels (total PAHs, 1,610 ng/g; Nap, 176 $\mathrm{ng} / \mathrm{g}$; Phe, $204 \mathrm{ng} / \mathrm{g}$ ). It can be concluded that the concentrations of DDTs, HCHs and PAHs were also lower than the values that could cause ecological risks.

\section{Conclusions}

We analyzed the contamination status and possible sources of OCPs and PAHs in the surface water and sediments of Bosten Lake, in Xinjiang of China. Compared to lakes in the other regions of China that have experienced intensive agricultural or industrial activities, residues of OCPs in Bosten Lake are relatively low. But, they are relatively higher compared to the values of the lakes in developed countries. PAH concentrations in Bosten Lake were relatively lower than those in lakes surrounded by intensive industrial activities. The spatial distributions of contaminants in Bosten Lake suggest that local agricultural runoff, domestic sewage, and industrial wastewater caused most of the pollution. Composition analysis showed that both industrial products and lindane uses were the main pollution sources for HCHs. DDT pollution was primarily derived from the historical residues in water and recent inputs of DDTs in sediments. The main sources of PAHs were petroleum and low-temperature combustion of wood and coal. Comparison of OCP and PAH concentrations in Bosten Lake with existing quality guideline values suggests that risks from these pollutants are relatively low in Bosten Lake. 


\section{Acknowledgements}

This research was funded by the National Natural Science Foundation of China (41471173; 41671200; U1603242) and the Specific Scientific Research Fund from the Ministry of Environmental Protection of the People's Republic of China (201309041). We thank Prof. GAO Guang, Dr. TANG Xiangming and Dr. ZENG Hai'ao for their helps in the field, and Professor Mark BRENNER for his valuable supports in language improvements. We also thank anonymous reviewers and the journal editors for their helpful comments and suggestions.

\section{References}

Arienzo M, Albanese S, Lima A, et al. 2015. Assessment of the concentrations of polycyclic aromatic hydrocarbons and organochlorine pesticides in soils from the Sarno River basin, Italy, and ecotoxicological survey by Daphnia magna. Environmental Monitoring and Assessment, 187(2): 1-14.

Dai G, Liu X, Liang G, et al. 2011. Distribution of organochlorine pesticides (OCPs) and poly chlorinated biphenyls (PCBs) in surface water and sediments from Baiyangdian Lake in North China. Journal of Environmental Sciences, 23(10): 16401649.

Dai G, Liu X, Liang G, et al. 2014. Evaluating the exchange of DDTs between sediment and water in a major lake in North China. Environmental Science and Pollution Research, 21(6): 4516-4526.

Franců E, Schwarzbauer J, Lána R, et al. 2010. Historical changes in levels of organic pollutants in sediment cores from Brno Reservoir, Czech Republic. Water, Air and Soil Pollution, 209(1-4): 81-91.

Guo J, Wu F, Luo X, et al. 2010. Anthropogenic input of polycyclic aromatic hydrocarbons into five lakes in western China. Environmental Pollution, 158(6): 2175-2180.

Harrison R M, Smith D J T, Luhana L. 1996. Source apportionment of atmospheric polycyclic aromatic hydrocarbons collected from an urban location in Birmingham, UK. Environmental Science and Technology, 30(3): 825-832.

Helm P A, Milne J, Hiriart-Baer V, et al. 2011. Lake-wide distribution and depositional history of current-and past-use persistent organic pollutants in Lake Simcoe, Ontario, Canada. Journal of Great Lakes Research, 37: 132-141.

Iwata H, Tanabe S, Ueda K, et al. 1995. Persistent organochlorine residues in air, water, sediments, and soils from the lake Baikal region, Russia. Environmental Science and Technology, 29(3): 792-801.

Khairy M A, Lohmann R. 2012. Field validation of polyethylene passive air samplers for parent and alkylated PAHs in Alexandria, Egypt. Environmental Science and Technology, 46(7): 3990-3998.

Kim K H, Jahan S A, Kabir E, et al. 2013. A review of airborne polycyclic aromatic hydrocarbons (PAHs) and their human health effects. Environment International, 60: 71-80.

Li C, Huo S, Yu Z, et al. 2014. Spatial distribution, potential risk assessment, and source apportionment of polycyclic aromatic hydrocarbons (PAHs) in sediments of Lake Chaohu, China. Environmental Science and Pollution Research, 21(20): 1202812039.

Lin T, Hu Z, Zhang G, et al. 2009. Levels and mass burden of DDTs in sediments from fishing harbors: the importance of DDT-containing antifouling paint to the coastal environment of China. Environmental Science and Technology, 43: 80338038.

Liu W X, He W, Qin N, et al. 2013. The residues, distribution, and partition of organochlorine pesticides in the water, suspended solids, and sediments from a large Chinese lake (Lake Chaohu) during the high water level period. Environmental Science and Pollution Research, 20(4): 2033-2045.

Liu X, Xu M, Yang Z, et al. 2010. Sources and risk of polycyclic aromatic hydrocarbons in Baiyangdian Lake, North China. Journal of Environmental Science and Health Part A, 45(4): 413-420.

Liu Y, Yu N, Li Z, et al. 2012. Sedimentary record of PAHs in the Liangtan River and its relation to socioeconomic development of Chongqing, Southwest China. Chemosphere, 89(7): 893-899.

Liu Y, Mu S, Bao A, et al. 2015. Effects of salinity and (an) ions on arsenic behavior in sediment of Bosten Lake, Northwest China. Environmental Earth Sciences, 73(8): 4707-4716.

Lu M, Zeng D C, Liao Y, et al. 2012. Distribution and characterization of organochlorine pesticides and polycyclic aromatic hydrocarbons in surface sediment from Poyang Lake, China. Science of the Total Environment, 433: 491-497.

Ma L, Wu J, Abuduwaili J. 2011. The climatic and hydrological changes and environmental responses recorded in lake sediments of Xinjiang, China. Journal of Arid Land, 3(1): 1-8.

MacDonald D D, Ingersoll C G, Berger T A. 2000. Development and evaluation of consensus-based sediment quality guidelines 
for freshwater ecosystems. Archives of Environmental Contamination and Toxicology, 39(1): 20-31.

Mackay D. 2001. Multimedia Environmental Models: the Fugacity Approach (2 ${ }^{\text {nd }}$ ed.) CRC Press: Boca Raton, 69-232.

Montuori P, Triassi M. 2012. Polycyclic aromatic hydrocarbons loads into the Mediterranean Sea: estimate of Sarno River inputs. Marine Pollution Bulletin, 64: 512-520.

Montuori P, Cirillo T, Fasano E, et al. 2014. Spatial distribution and partitioning of polychlorinated biphenyl and organochlorine pesticide in water and sediment from Sarno River and Estuary, Southern Italy. Environmental Science and Pollution Research, 21(7): 5023-5035.

National Bureau of Statistics of China. 2009. China Statistical Yearbook 2009 . Beijing: China Statistics Press. (in Chinese)

Ogata M, Fujisawa K. 1990. Gas chromatographic and capillary gas chromatographic/mass spectrometric determination of organic sulfur compounds in sediment from ports: significance of these compounds as an oil pollution index. Bulletin of Environmental Contamination and Toxicology, 44(6): 884-891.

Ok G, Shirapova G, Matafonova G, et al. 2013. Characteristics of PAHs, PCDD/Fs, PCBs and PBDEs in the sediment of Lake Baikal, Russia. Polycyclic Aromatic Compounds, 33: 173-192.

Qiu X, Zhu T, Li J, et al. 2004. Organochlorine pesticides in the air around the Taihu Lake, China. Environmental Science and Technology, 38(5): 1368-1374.

Qiu X, Zhu T, Yao B, et al. 2005. Contribution of dicofol to the current DDT pollution in China. Environmental Science and Technology, 39(12): 4385-4390.

Santschi P H., Presley B J, Wade T L, et al. 2001. History contamination of PAHs, PCBs, DDTs, and heavy metals in Mississippi River Delta, Galveston Bay and Tampa Bay Sediment cores. Marine Environmental Research, 52: 51-79.

UNEP Chemicals. 2002. Regional reports of the regionally based assessment of persistent toxic substances program. [2013-11-25]. http://www.chem.unep.ch/pts.

USEPA. 2002. Current national recommended water quality criteria. [2014-03-15]. http://www.epa.gov/waterscience/criteria/ wqcriteria.html.

Willett K L, Ulrich E M, Hites R A. 1998. Differential toxicity and environmental fates of hexachlorocyclohexane isomers. Environmental Science and Technology, 32(15): 2197-2207.

Wu J, Liu W, Zeng H, et al. 2014. Water quantity and quality of six lakes in the arid Xinjiang region, NW China. Environmental Processes, 1(2): 115-125.

Zhang C, Feng Z, Yang Q, et al. 2010. Holocene environmental variations recorded by organic-related and carbonate-related proxies of the lacustrine sediments from Bosten Lake, northwestern China. The Holocene, 20(3): 363-373.

Zhang L, Dong L, Shi S, et al. 2009. Organochlorine pesticides contamination in surface soils from two pesticide factories in Southeast China. Chemosphere, 77: 628-633.

Zhang Y, Lu Y, Xu J, et al. 2011. Spatial distribution of polycyclic aromatic hydrocarbons from Lake Taihu, China. Bulletin of Environmental Contamination and Toxicology, 87(1): 80-85.

Zhang Z L, Hong H S, Zhou J L, et al. 2003. Fate and assessment of persistent organic pollutants in water and sediment from Minjiang River Estuary, Southeast China. Chemosphere, 52(9): 1423-1430.

Zhao Z, Zhang L, Wu J, et al. 2009. Distribution and bioaccumulation of organochlorine pesticides in surface sediments and benthic organisms from Taihu Lake, China. Chemosphere, 77(9): 1191-1198.

Zhi H, Zhao Z, Zhang L. 2015. The fate of polycyclic aromatic hydrocarbons (PAHs) and organochlorine pesticides (OCPs) in water from Poyang Lake, the largest freshwater lake in China. Chemosphere, 119: 1134-1140. 